\title{
Study of Hypervelocity Projectile Impact on Thick Metal Plates
}

\author{
Shawoon K. Roy, ${ }^{1}$ Mohamed Trabia, ${ }^{1}$ Brendan O'Toole, ${ }^{1}$ Robert Hixson, ${ }^{2}$ \\ Steven Becker, ${ }^{2}$ Michael Pena, ${ }^{2}$ Richard Jennings, ${ }^{1}$ Deepak Somasoundaram, ${ }^{1}$ \\ Melissa Matthes, ${ }^{1}$ Edward Daykin, ${ }^{2}$ and Eric Machorro ${ }^{2}$ \\ ${ }^{1}$ Department of Mechanical Engineering, University of Nevada, Las Vegas, NV 89154, USA \\ ${ }^{2}$ National Security Technologies, LLC, Las Vegas, NV 89030, USA \\ Correspondence should be addressed to Mohamed Trabia; mohamed.trabia@unlv.edu
}

Received 9 April 2015; Accepted 27 September 2015

Academic Editor: Marcello Vanali

Copyright (C) 2016 Shawoon K. Roy et al. This is an open access article distributed under the Creative Commons Attribution License, which permits unrestricted use, distribution, and reproduction in any medium, provided the original work is properly cited.

\begin{abstract}
Hypervelocity impacts generate extreme pressure and shock waves in impacted targets that undergo severe localized deformation within a few microseconds. These impact experiments pose unique challenges in terms of obtaining accurate measurements. Similarly, simulating these experiments is not straightforward. This study proposed an approach to experimentally measure the velocity of the back surface of an A36 steel plate impacted by a projectile. All experiments used a combination of a two-stage light-gas gun and the photonic Doppler velocimetry (PDV) technique. The experimental data were used to benchmark and verify computational studies. Two different finite-element methods were used to simulate the experiments: Lagrangian-based smooth particle hydrodynamics (SPH) and Eulerian-based hydrocode. Both codes used the Johnson-Cook material model and the MieGrüneisen equation of state. Experiments and simulations were compared based on the physical damage area and the back surface velocity. The results of this study showed that the proposed simulation approaches could be used to reduce the need for expensive experiments.
\end{abstract}

\section{Introduction}

Hypervelocity impact events are ubiquitous in many areas, including micrometeoroid collision with spacecraft, projectile impacts, and when modeling effects of explosives on structures. Consequently, researchers have been studying various aspects of this problem for several decades. A common technique to study hypervelocity impact in laboratory settings is the two-stage light-gas gun $[1,2]$, which can accelerate a projectile to generate shock waves in a target similar to those created by detonating high explosives or meteorite collisions [3]. Swift [4] discussed the historical development of this type of gun.

Under hypervelocity impact conditions, thin metallic plates tend to stretch and bend around the impact area, absorbing a significant part of the projectile's kinetic energy before perforation occurs. On the other hand, thick plates experience several failure modes during impact, such as spalling, petalling, discing, and plugging [5]. These failure modes depend upon several factors, such as the impact velocity, the properties of the plate material, and the geometry of the projectile. Spalling, which is of a particular interest in this study, occurs when a triangular-shaped stress wave is reflected from the back of the target plate, thereby creating a tensile pressure that is greater than the material strength [6], which then results in an internal crack that progresses normal to the direction of the wave.

Goldsmith et al. [7] studied and developed analytical models for the elastic-plastic plate deformation of aluminum plates impacted by a hard-steel cylindrical-nose projectile. Failure modes for rod penetration experiments under hypervelocity impact conditions have been studied only by a relatively small number of researchers [8]. Christman and Gehrig [9] studied the penetration mechanics and cratering processes in metallic and nonmetallic targets at impact velocities from 0.3 to $6.7 \mathrm{~km} / \mathrm{s}$. Sorensen et al. [10] studied 
penetration mechanics of semi-infinite rolled homogeneous armor (RHA) steel by monolithic projectiles and segmented penetrators at velocities ranging from 2.5 to $4.0 \mathrm{~km} / \mathrm{s}$. Subsequent studies on spall fracture and dynamic response of materials were reviewed by Oscarson and Graff [6]. Shockey et al. [11] reported that different projectile materials cause different types of physical damage to steel plates under hypervelocity impact. In addition, they reported microstructural changes and the pressure induced $\alpha \rightleftarrows \varepsilon$ polymorphic transition of the steel plates during impact. The penetration behavior of long rod tungsten-alloy projectiles in highhard armor steel plates was studied by Anderson et al. [12] at two impact velocities, $1.25 \mathrm{~km} / \mathrm{s}$ and $1.70 \mathrm{~km} / \mathrm{s}$. Bond [13] suggested that spallation damage and phase-transition kinetics were important in damage studies of martensitic steel armor when subjected to hypervelocity impact.

Merzhievskii and Titov [14] evaluated the perforation and deformation of thin steel plates at velocities from 3 to $9 \mathrm{~km} / \mathrm{s}$; they developed an analytical method to relate debris particles to the impact velocity. The ballistic limits of aluminum plates of various thicknesses were studied by Børvik et al. [15] using a compressed-air gas gun. An analytical model was developed based on those limits. Analytical models were developed to predict the cratering, depth of penetration, and perforation of semi-infinite target plates by long rod penetrators by Wen et al. [16-18].

Recent work on impact dynamics and shock physics of materials has emphasized the use of velocimetry data in flyer plate experiments to characterize the equation of state, spall strength, polymorphic phase transition, and the Hugoniot elastic limit of materials. Velocimetry data can provide a clear representation of the response of materials under high pressure and high strain rates, which may lead to developing accurate predictive computational models for materials. The following is a brief overview of velocimetry diagnostic techniques. Barker and Hollenbach developed the homodyne interferometry technique: Velocity Interferometer System for Any Reflector (VISAR) system [19]. This technique became widely popular within the shock physics community. Numerous impact and shock studies have used VISAR as the primary diagnostic tool [20-28]. However, complexity, cost, and various issues that cannot be easily resolved, such as obtaining velocities from multiple points on a moving surface, prompted the development of an alternative diagnostic tool known as photonic Doppler velocimetry (PDV), a displacement interferometer that collects velocity data based on measuring displacement using optical fiber probes [29]. Advantages of PDV include its relative simplicity, robustness, cost, accuracy, and versatility [30]. Chau et al. [31] used PDV for shock Hugoniot measurements of a singlecrystal copper plate during impact experiments.

Accurate predictive modeling of impact events under hypervelocity conditions can provide a less expensive alternative to conducting actual experiments. However, these numerical simulations require the identification of a large number of parameters that are needed to describe the nonlinearities of the problem. In many cases, hypervelocity impact simulation models are based on many simplifications that affect the accuracy of these simulations. One feature of hypervelocity impacts is that solid materials behave somewhat like fluids after the initial elastic-plastic transition. Therefore, it is appropriate to model plate penetration using hydrodynamic techniques having a separately defined strength model. Recently, a considerable effort has gone into developing models that deal with perforation and penetration problems. For example, it was shown that an accurate computational model of impact depends on the selection of the proper physics models and input parameters [32]. Several constitutive models were developed over the years to simulate hypervelocity impact events. Johnson and Cook [33] developed a constitutive model for materials subjected to large strains, high strain rates, and high temperatures. Two other flow stress models were developed for plastic deformation of ductile materials: Zerilli-Armstrong [34] and SteinbergCochran-Guinan-Lund model [35]. A comparative study of all these models was performed by Banerjee [36]. Beside all of these constitutive relations, equation of state (EOS) models were developed to understand the dynamic behavior of materials under shock loading and were often used in this type of simulations. Børvik et al. simulated perforation phenomena in LS-DYNA [37], using a constitutive material model $[38,39]$ that combined viscosity and ductile damage. Additionally, plate perforation with various nose shapes for projectiles was simulated [40-42] using the viscoplastic relationship described in [39]. Eftis and Nemes simulated ductile spall fracture and postspall behavior of a circular plate, using the PRONTO finite element code where a viscoplastic constitutive relationship was implemented that included the microvoid volume fraction as a scalar material damage variable [43]. Recently, several computational packages based on hydrocode methods that simulate events are associated with extreme high-pressure dynamics [44]. This technique has been used for penetration modeling of different steel plates such as Eulerian-based CTH hydrocode [12, 45-47]. All these works [45-47] listed Mie-Grüneisen EOS in their simulation work.

Another simulation approach is to use the Lagrangianbased method of smooth particle hydrodynamics (SPH) technique [48], a meshless Lagrangian numerical method that can address the problems associated with the large geometric distortions where typical grid-based mesh techniques have difficulties. The SPH technique has recently gained popularity in simulating impact-penetration problems [4953]. Johnson-Cook model was used as the primary strength model in [49] and Mie-Grüneisen EOS was listed in [51].

Although numerous studies describe the perforation and penetration mechanics of plates during hypervelocity impact, only a few discussed the plastic deformation of plates that do not experience complete penetration under such conditions [13].

This study presents velocimetry data captured by a PDV system in experiments using a two-stage light-gas gun to understand the plastic-deformation behavior of A36 steel plates that have not had full penetration. Two computational approaches were developed to simulate the experiments. Results were compared with each other and to the experimental data. 


\section{Materials and Methods}

2.1. Materials. All gas gun experiments in this study used Lexan projectiles, cylinders $5.6 \mathrm{~mm}$ in diameter and $8.6 \mathrm{~mm}$ in length. Depending on the fill pressure of the gas used, the projectile velocity varied from about 4.5 to $6 \mathrm{~km} / \mathrm{s}$. The dimensions of the ASTM A36 steel target plates were $152.4 \times$ $152.4 \times 12.7 \mathrm{~mm}$. The thickness of the target plates was chosen to prevent their complete penetration due to projectile impacts at these velocities. Young's modulus $(E)$ for this Lexan and A36 steel used in all experiments was $2.54 \mathrm{GPa}$ and $200 \mathrm{GPa}$, respectively.

2.2. Methods. A two-stage light-gas gun, Figure 1, was used to perform the hypervelocity impact experiments. The main components of the gas gun are the powder breech, pump tube, central breech, launch tube, blast tank, and target chamber.

The experiments were conducted according to the following steps. A cartridge, filled with gunpowder, was fired using a solenoid pin. The resulting explosion propelled a piston in the pump tube filled with pressurized helium gas. As the piston moved, it increased the pressure of the helium, which eventually breaks a petal valve. The gas then accelerated the projectile, which was placed immediately behind the petal valve in the launch tube, through the blast tank and the drift tube, until it would impact the target within the target chamber.

The target plates were bolted using four $12.7 \mathrm{~mm}\left(1 / 2^{\prime \prime}\right)$ SAE Grade 5 bolts onto a mounting plate that was attached to the walls of the target chamber, Figure 2.

The velocity of the projectile was measured by a laser intervalometer system having two stations separated by a fixed distance. Each station had a laser source that directed a beam through a port to a narrow band-pass filter to ensure that a 32-photodiode array was free of any contamination by external light. Measuring the time interval was initiated by the flight of the projectile across the first station and terminated when it passed through the second station. The time interval was recorded using a digitizer.

Free surface velocity from the target was measured using a PDV system. The basic working principle of a single channel PDV system is described in Figure 3 [29]; however, a brief overview is presented. A laser light is fed into an optical fiber probe. The reference source light (typically at a wavelength, $\lambda$, of $1550 \mathrm{~nm}$ ) is reflected from the measured moving surface. The resulting Doppler shifted light is sent to a detector to produce fringes, each of which corresponds to the displacement of the surface by a wavelength difference of $\lambda / 2$ between reflected and reference lights. These displacementtime signals are recorded by a high-speed digitizer. The PDV was completely enclosed.

In all gas gun experiments, the PDV optical fiber probe was placed in a holder and aimed at the center of the back surface of the target plate, Figure 4 . The target surface was polished by using different-grit sand papers and ball roller beforehand to reflect light at certain intensity. The PDV system was triggered few microseconds after the projectile passed through the second station of the intervalometer. This delay was based on the projectile velocity and the distance to

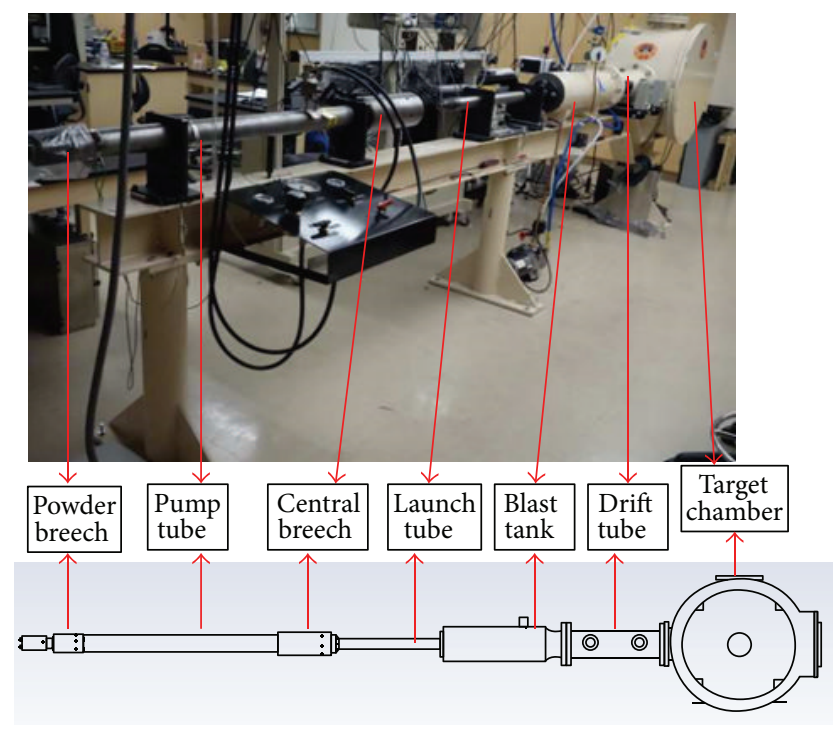

FIGURE 1: Two-stage light-gas gun.

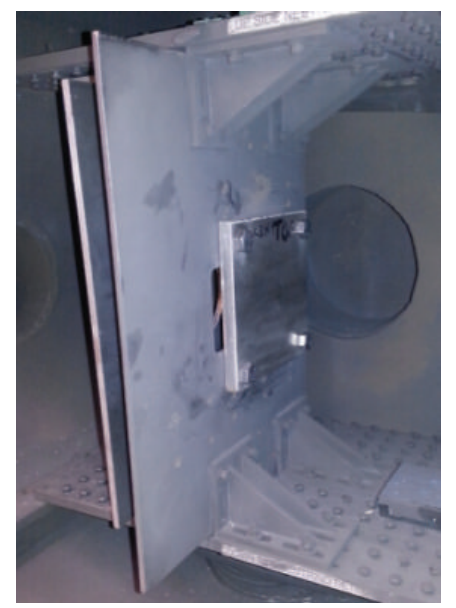

FIGURE 2: Target plate bolted inside the gas gun chamber.

the target plate was used to initiate the PDV data collection. Once a digitizer recorded the data, a fast Fourier transform was performed to obtain the measured point velocity based on the recorded displacement data.

Figure 4 shows the layout of the experiment. After testing, physical measurements of the impact crater and the resulting back surface bulge were recorded. The target plates were sectioned to check for spall damage.

\section{Experimental Results}

In all gas gun experiments, the Lexan projectiles disintegrated completely. A small crater was created as a result of the impact, with a bulge on the back side of the target plate. Crater details and bulge dimensions are listed in Table 1. In all gas gun experiments, the impact location varied within $3 \mathrm{~mm}$ of the geometric center of the plate. A typical sectioned target plate showed that spall had occurred inside the material, 
TABLE 1: Physical dimensions of the crater and bulge after impact.

\begin{tabular}{lcccc}
\hline Test ID & $\begin{array}{c}\text { Impact } \\
\text { velocity } \\
(\mathrm{m} / \mathrm{s})\end{array}$ & $\begin{array}{c}\text { Crater } \\
\text { diameter } \\
(\mathrm{mm})\end{array}$ & $\begin{array}{c}\text { Penetration } \\
(\mathrm{mm})\end{array}$ & $\begin{array}{c}\text { Bulge } \\
(\mathrm{mm})\end{array}$ \\
\hline $1000-016$ & 5338 & 17.0 & 6.3 & 2.3 \\
$1000-017$ & 5063 & 16.9 & 5.8 & 2.3 \\
\hline
\end{tabular}

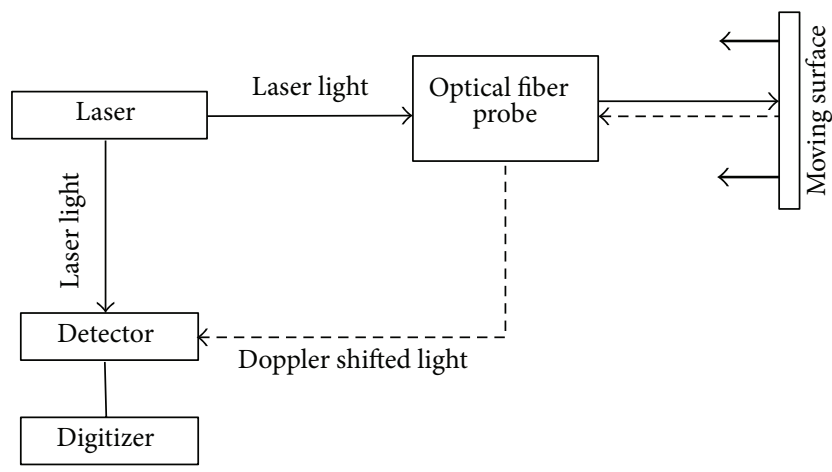

FIgURE 3: Basic principle of a single channel PDV system (based on [29]).

Figure 5. Table 2 summarizes the spall cracking in the two experiments.

Figure 6 shows typical velocimetry data from a single channel PDV. The duration of the projectile-target interaction typically lasted for $25 \mu \mathrm{s}$. The first $5 \mu \mathrm{s}$ displayed the most characteristic features of the hypervelocity impact, namely, elastic precursor wave, HEL, plastic wave propagation, spall signature, and elastic loading and unloading. A brief discussion of these features follows.

When material is loaded in extreme pressure, the shockwave creates an elastic response up to certain limit. This limit is usually defined by HEL, which is usually known as the elastic precursor wave. After this limit, material flows plastically due to the strong shockwave propagation. In the case of uniaxial strain, the peak velocity is followed by multiple loading and unloading phase. The first drop from the peak velocity and subsequent loading-unloading zones are associated with the spall signature in metals. Typically, the first spall signature in metals is followed by a significant sharp drop in free surface velocity, which is defined as the elastic unloading stage.

\section{Numerical Simulations}

This study described two approaches to simulate the experiments described in the previous section: a smooth particle hydrodynamics (SPH) solver in LS-DYNA software and the combined hydro, radiation, and transport diffusion (CTH) hydrocode. The remainder of this section details model development.

4.1. Material Model. Both the LS-DYNA SPH and the CTH computer codes used the Johnson-Cook material model [10] for both the Lexan projectile and A36 steel plate. In the Johnson-Cook material model of plasticity, flow stress is expressed as

$$
\sigma_{y}=\left(A+B\left(\varepsilon^{p}\right)^{n}\right)\left(1+C \ln \left(\varepsilon^{* *}\right)\right)\left(1-\left(T^{*}\right)^{m}\right),
$$

where $\sigma_{y}$ is the flow stress; $A, B, C, n$, and $m$ were material constants; $\varepsilon^{p}$ is the effective plastic strain; and $\varepsilon^{* *}$ is the effective total strain rate normalized by quasistatic strain rate. The homologous temperature, $T^{*}$, is defined as

$$
T^{*}=\frac{T-T_{r}}{T_{m}-T_{r}},
$$

where $T_{r}$ and $T_{m}$ were room and the melting temperatures in Kelvin, respectively.

All the parameters of the Johnson-Cook model for Lexan [54] and A36 steel [55] are listed in Table 3.

4.2. Equation of State (EOS). Materials under shock wave loading needed a shock model that could account for the sudden pressure, temperature, internal energy, and density changes that occur in front of the shock waves. The equation of state (EOS) of a material is a general thermodynamic relation that is defined by the code user. Various forms of EOS were used to describe the volumetric compression or expansion behavior of different types of materials. One of the most commonly used EOS is the Mie-Grüneisen equation of state, which can be expressed [58] as

$$
\begin{aligned}
& P \\
& =\frac{\rho_{0} C_{0}{ }^{2} \mu\left(1+\left(1-\gamma_{0} / 2\right) \mu-(a / 2) \mu^{2}\right)}{\left(1-\left(S_{1}-1\right) \mu-S_{2}\left(\mu^{2} /(\mu+1)\right)-S_{3}\left(\mu^{3} /(\mu+1)^{2}\right)\right)^{2}} \\
& \quad+\left(\gamma_{0}+a \mu\right) E,
\end{aligned}
$$

where $P$ is the pressure; $S_{1}, S_{2}$, and $S_{3}$ are the coefficients of slope of shock velocity-particle velocity curve, $\gamma_{0}$ is the Grüneisen coefficient; $a$ is the volume correction factor; $\rho$ is the instantaneous density; $C_{0}$ is the Hugoniot intercept of the metal; $E$ is the internal energy; and $\mu=\left(\rho / \rho_{0}-1\right)$, where $\rho_{0}$ is the reference density. For materials under compression, a temperature-corrected form of the above equation is given in the following [59]:

$$
P=\frac{\rho_{0} C_{0}{ }^{2} \mu\left(1+\left(1-\gamma_{0} / 2\right) \mu\right)}{\left(1-\left(S_{1}-1\right) \mu\right)^{2}}+\gamma_{0} E .
$$

Assuming a negligible change in density and internal energy, the above equations can be rewritten as

$$
P=\frac{\rho_{0} C_{0}^{2}\left(2-\gamma_{0} / 2\right)}{\left(1-S_{1}\right)^{2}} .
$$

Both LS-DYNA and CTH included a Grüneisen EOS for Lexan and A36 steel; these were used in simulations during this study, using the input parameters listed in Table 4. 
TABLE 2: Details of spall crack in sectioned plates.

\begin{tabular}{lcccc}
\hline Test ID & Impact velocity $(\mathrm{m} / \mathrm{s})$ & Crack diameter $(\mathrm{mm})$ & Crack width $(\mathrm{mm})$ & $\begin{array}{c}\text { Spall crack location with } \\
\text { respect to free surface }(\mathrm{mm})\end{array}$ \\
\hline $1000-016$ & 5338 & 18.5 & 1.8 & 2.3 \\
$1000-017$ & 5063 & 18.5 & 1.7 & 2.4 \\
\hline
\end{tabular}

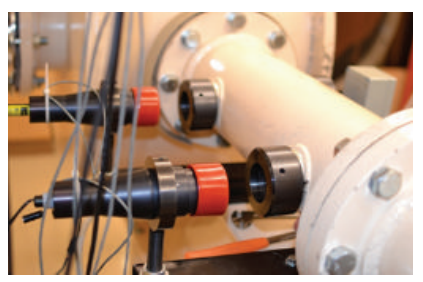

Laser trigger

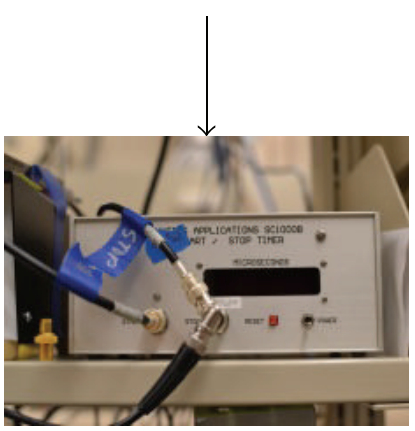

Intervalometer

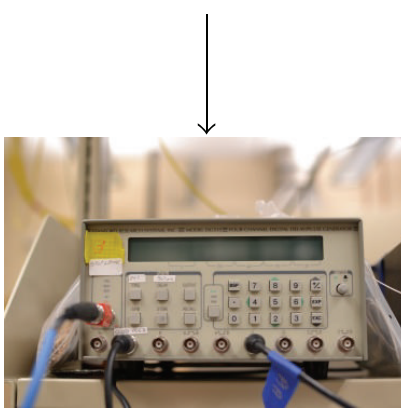

Delay generator

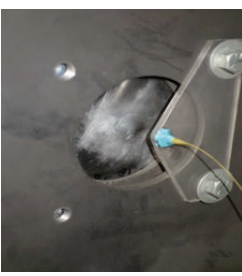

Laser probe

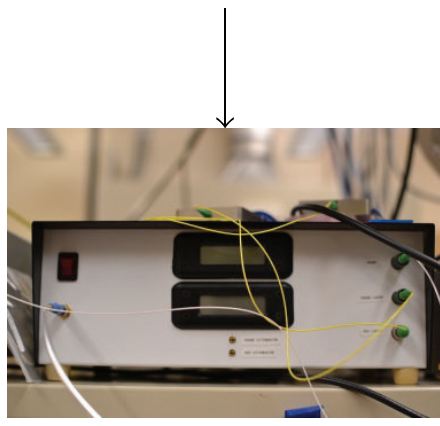

Probe attenuator

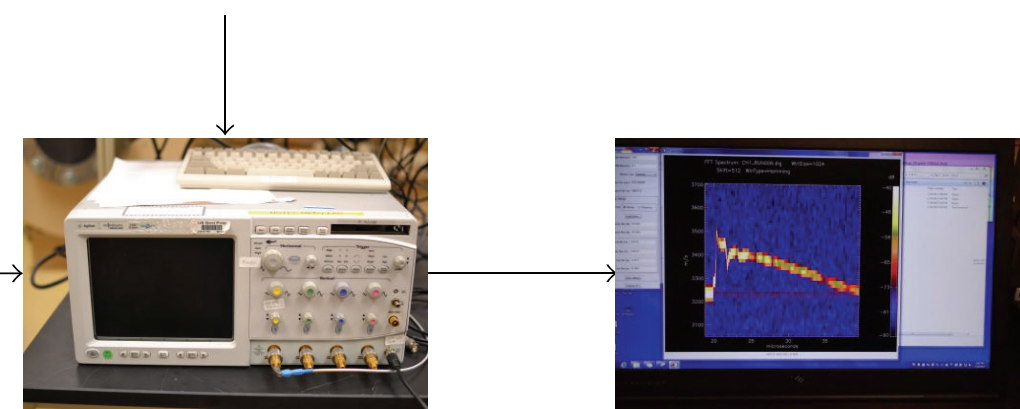

PDV oscilloscope

Processed signal

FIgURE 4: Layout of the PDV data acquisition.

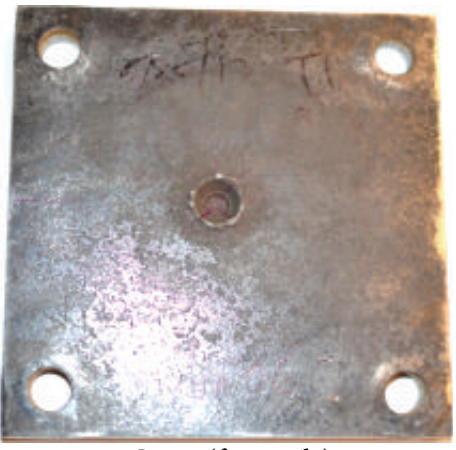

Crater (front side)

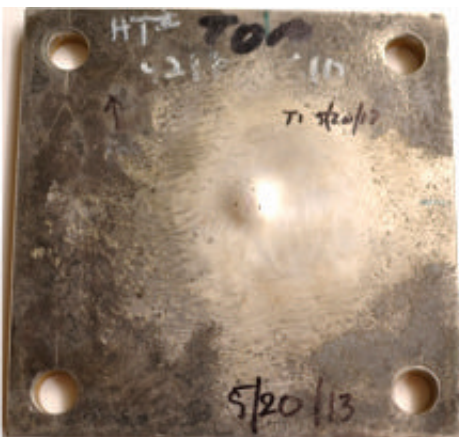

Bulge (back side)

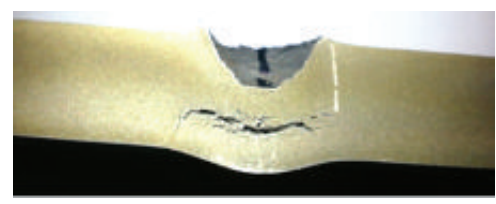

Spall (sectioned)

Figure 5: Typical target plate after an experiment. 
TABLE 3: Johnson-Cook material properties for the projectile and the target.

\begin{tabular}{lcccccccc}
\hline Material & $A(\mathrm{MPa})$ & $B(\mathrm{MPa})$ & $C$ & $M$ & $n$ & $T_{m}$ (Kelvin) & $\nu^{\dagger}$ & EPSO \\
\hline Lexan [54] & 75.8 & 68.9 & 0 & 1.85 & 1.004 & 533 & 0.344 \\
A36 steel [55] & 286.1 & 500.1 & 0.022 & 0.917 & 0.2282 & 1811 & 0.260 & 1 \\
\hline
\end{tabular}

${ }^{\dagger} v$ is Poisson's ratio.

TABLE 4: EOS parameters for the projectile and the target.

\begin{tabular}{lcccc}
\hline Material & $\rho_{0}\left(\mathrm{~kg} / \mathrm{m}^{3}\right)$ & $C_{0}(\mathrm{~m} / \mathrm{s})$ & $S_{1}$ & $\gamma_{0}$ \\
\hline Lexan [56] & 1190 & 1933 & $1.42^{\dagger \dagger}$ & 0.61 \\
A36 steel [57] & 7890 & 4569 & 1.49 & 2.17 \\
\hline
\end{tabular}

${ }^{\dagger \dagger} S_{1}$ value for Lexan is suggested as 1.42 [55].

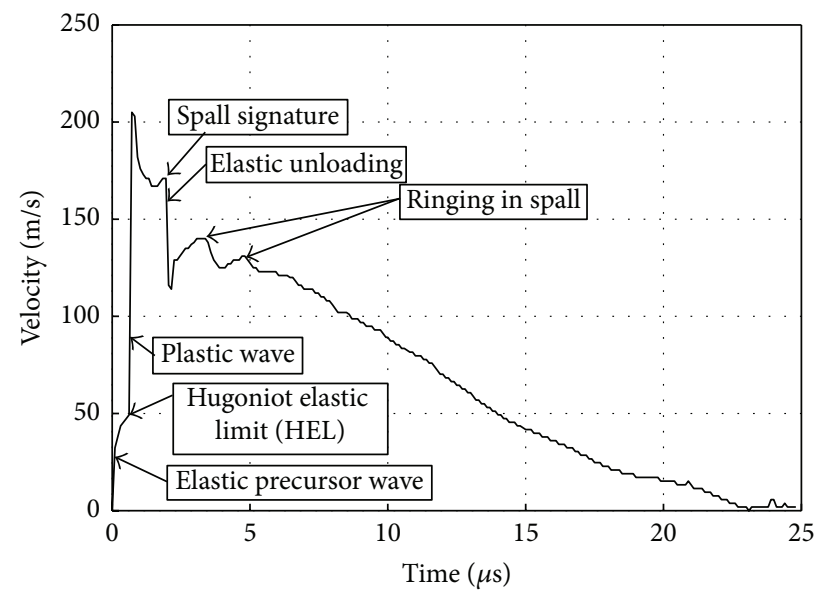

— Test ID 1000-017

FIGURE 6: Typical free surface velocity data as obtained by a PDV system.

\subsection{Estimation of the Hugoniot Elastic Limit and Spall Strength} of A36 Steel. In most fundamental shock studies, velocimetry data are obtained from uniaxial strain experiments on the shock Hugoniot. This work considered the case of a projectile plate penetration experiment that can be described using axisymmetric assumptions. The Hugoniot elastic limit and spall strength were calculated based on the uniaxial case in the absence of axisymmetric data.

The approximate Hugoniot elastic limit, $\sigma_{\mathrm{HEL}}$, and spall strength, $\sigma_{\text {spall }}$, of A36 steel were calculated from this velocity profile by assuming that the impact was a one-dimensional localized phenomenon with the following relations [28]:

$$
\begin{gathered}
\sigma_{\mathrm{HEL}}=\frac{1}{2} \Delta U_{H} \rho_{0} c_{l}, \\
\sigma_{\text {spall }}=\frac{1}{2} \Delta U_{\mathrm{fs}} \rho_{0} c_{b},
\end{gathered}
$$

where $\Delta U_{H}$ was the free surface velocity at elastic precursor wave; $\Delta U_{\mathrm{fs}}$ was the pullback velocity of free surface as shown in Figure 7; and $c_{l}$ and $c_{b}$ correspond to the longitudinal and bulk sound speed, respectively. These speeds depend on

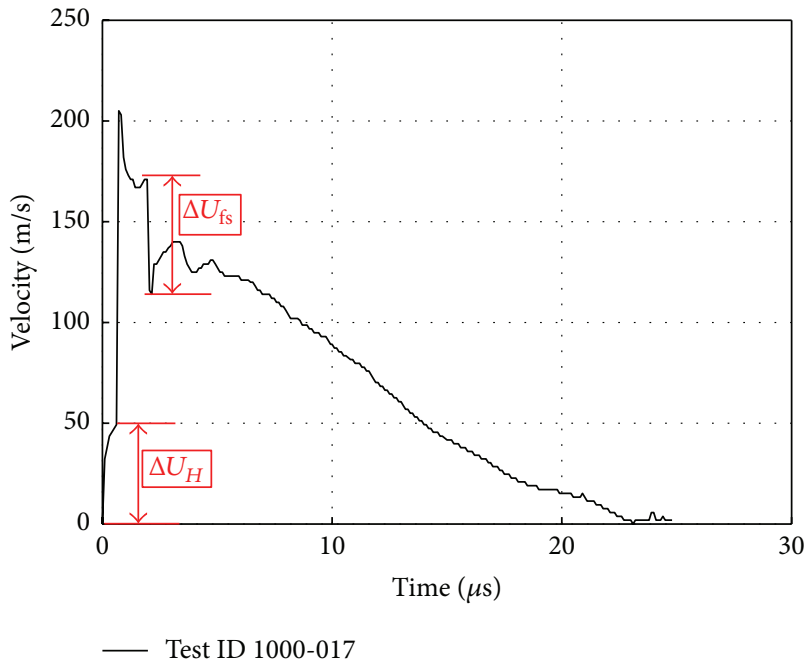

FIGURE 7: HEL and spall strength calculation for typical test.

Young's modulus, $E$, and the bulk modulus, $K$, of A36 steel. Equations are given as follows:

$$
\begin{aligned}
c_{l} & =\sqrt{\frac{E}{\rho}}, \\
c_{b} & =\sqrt{\frac{K}{\rho}},
\end{aligned}
$$

where $c_{l}$ and $c_{b}$ were calculated to be $5035 \mathrm{~m} / \mathrm{s}$ and $4212 \mathrm{~m} / \mathrm{s}$, respectively, for values of $200 \mathrm{GPa}$ [60] and $140 \mathrm{GPa}$ [60] of $E$ and $K$, respectively.

Based on these equations, the Hugoniot elastic limit and the spall strength of A36 steel were approximated based on the experiments and the above analysis; results are shown in Table 5.

Spalling of the material could be defined using either a pressure cut-off (Pmin) value in the Johnson-Cook model or a simple spall threshold parameter independent of the Johnson-Cook material-failure model. In this study, the first option was used to induce the spall in both LS-DYNA and CTH simulations. By taking the average of the two spall strength values of Table 5, a pressure cut-off value of $1.23 \mathrm{GPa}$ was determined.

4.4. Developing Simulation Models. The same two-dimensional (2D) axisymmetric geometry was used for both the SPH and the CTH simulations. The same material model, equations of the state, and boundary conditions were used in the CTH models. Because the shock did not reach 
TABLE 5: Hugoniot elastic limit and spall strength.

\begin{tabular}{lccccc}
\hline Test ID & Impact velocity $(\mathrm{m} / \mathrm{s})$ & $\Delta U_{H}(\mathrm{~m} / \mathrm{s})$ & $\sigma_{\mathrm{HEL}}(\mathrm{GPa})$ & $\Delta U_{\mathrm{fs}}(\mathrm{m} / \mathrm{s})$ & 91.2 \\
\hline $1000-016$ & 5338 & 61.22 & 1.22 & $\sigma_{\text {spall }}(\mathrm{GPa})$ \\
$1000-017$ & 5063 & 49.30 & 0.98 & 57 & 1.52 \\
\hline
\end{tabular}

the boundaries during the period of interest, it was decided that the target plates be modeled as cylindrical plates with a radius of $76.2 \mathrm{~mm}$. This assumption allowed the use of a $2 \mathrm{D}$ axisymmetric SPH model.

4.4.1. SPH in LS-DYNA. A body in an SPH model is represented by a set of particles that are placed in interpolation points within the body. The simulation primarily depends on an interpolation function called the smoothing length [49]. In addition, parameters such as particle density, bulk viscosity, and scale factors contribute to the quality of the solution.

Artificial bulk viscosity was included to dampen the numerical ringing and oscillations of the shock front. The artificial bulk viscosity parameters Q1 and Q2 are assigned values of 1.5 and 1.0 , respectively [61, 62]. No boundary conditions were defined for the model. Figure 8 shows the SPH model.

Several SPH particle spacing arrangements were tested while ensuring that the mass of each projectile particle was approximately equal to the mass of each target plate particle. All the simulation models were tested in a 46-core CentOS 5.6 system having LS-DYNA R 7.0 MPP (massively parallel processing) version. A summary of the free surface velocity profiles for different particle spacing was presented in Figure 9. The results showed that increasing the particle density resulted in a better representation of the elastic precursor wave. However, it was observed that increasing the particle density increases the peak velocity when compared with the experimental curve. Additionally, increasing the particle in the SPH model required significantly more computational time. Therefore, a particle spacing of $0.10 \mathrm{~mm}$ was selected for all subsequent SPH simulations.

4.4.2. CTH Model. A typical CTH model with a $0.10 \mathrm{~mm} \times$ $0.10 \mathrm{~mm}$ zone is shown in Figure 10. Zone-size studies recommended an optimal zone size of $0.10 \mathrm{~mm} \times 0.10 \mathrm{~mm}$ for all CTH models (Figure 11) as this zone density reasonably described the elastic wave and the sharp rise of the plastic wave.

4.5. Comparison of Simulation Results. Simulation results for LS-DYNA and CTH are shown in Figure 12. The results were compared with the experiments in terms of crater dimensions, spall details, and free surface velocity profiles.

As Table 6 shows, both techniques accurately captured the dimensions of the crater. The shorter simulation time within CTH $(10 \mu \mathrm{s})$ may explain the larger difference in the length of the back surface bulge dimension. LS-DYNA simulations showed higher magnitude of crater diameter and bulge for both experiments compared to CTH simulations. But LS-DYNA simulations underpredicted the crater depth

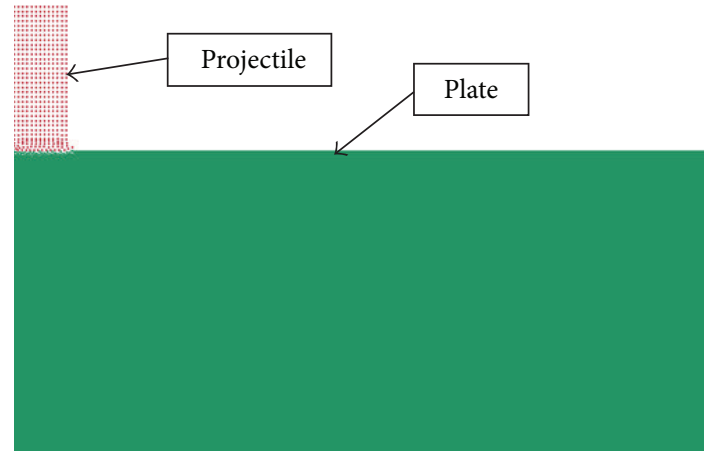

FIGURE 8: A typical SPH model (zoomed in) with $0.05 \mathrm{~mm}$ particle spacing.
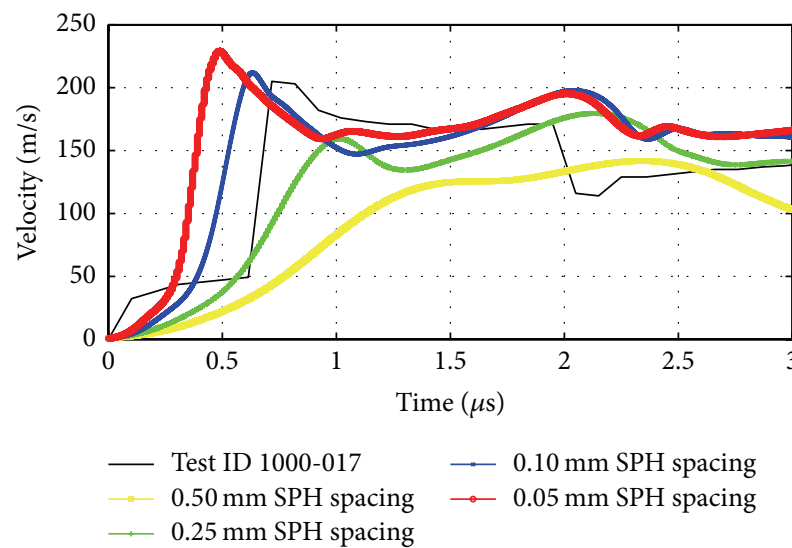

FIGURE 9: Typical SPH particle sensitivity study.

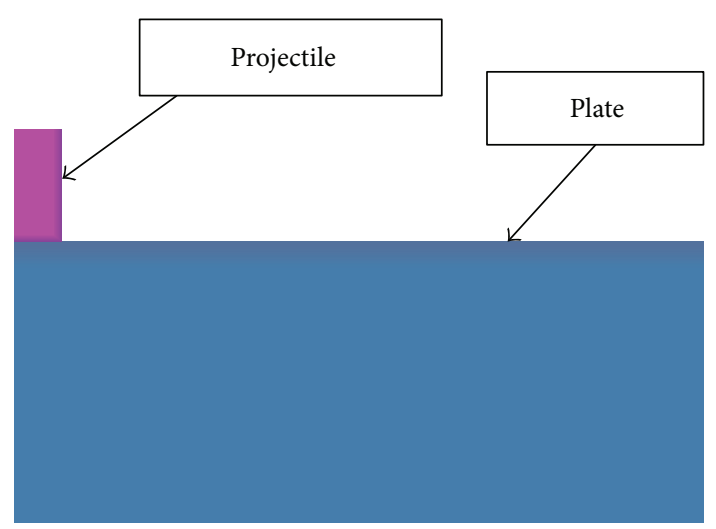

FIGURE 10: A typical CTH model with $0.10 \mathrm{~mm} \times 0.10 \mathrm{~mm}$ zone (zoomed in).

in case of $5063 \mathrm{~km} / \mathrm{s}$ impact experiment. The exact reason for this anomaly is yet to be understood; both codes captured the physical damage reasonably. 
TABLE 6: Physical comparison of the impact craters.

\begin{tabular}{|c|c|c|c|c|c|c|c|}
\hline $\begin{array}{l}\text { Impact } \\
\text { velocity } \\
(\mathrm{m} / \mathrm{s})\end{array}$ & Test ID & $\begin{array}{c}\text { Crater } \\
\text { diameter } \\
(\mathrm{mm})\end{array}$ & $\%$ difference & $\begin{array}{l}\text { Crater depth } \\
\quad(\mathrm{mm})\end{array}$ & $\%$ difference & $\begin{array}{l}\text { Back side bulge } \\
(\mathrm{mm})\end{array}$ & $\%$ difference \\
\hline \multirow{3}{*}{5338} & $1000-016$ & 17.0 & N/A & 6.3 & N/A & 2.3 & N/A \\
\hline & LS-DYNA & 17.1 & +0.6 & 5.9 & -7.1 & 2.1 & -8.1 \\
\hline & $\mathrm{CTH}$ & 15.7 & -7.6 & 5.7 & -9.3 & 2.0 & -19.5 \\
\hline \multirow{3}{*}{5063} & $1000-017$ & 16.9 & $\mathrm{~N} / \mathrm{A}$ & 5.8 & N/A & 2.4 & N/A \\
\hline & LS-DYNA & 15.9 & -5.9 & 5.0 & -13.8 & 2.2 & -7.8 \\
\hline & $\mathrm{CTH}$ & 15.7 & -7.1 & 5.7 & -1.7 & 1.9 & -12.9 \\
\hline
\end{tabular}

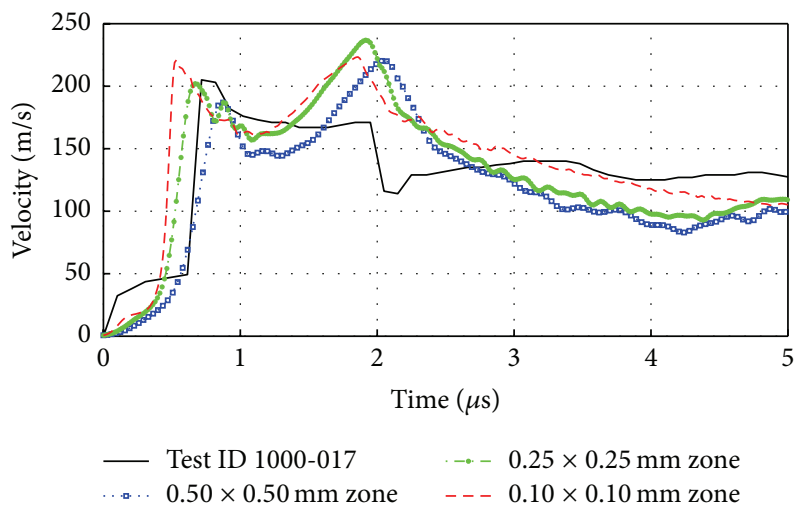

FIGURE 11: A typical CTH zone-sensitivity study with a $1200 \mathrm{MPa}$ spall strength.

Additionally, spall damage was monitored in both simulations. These simulations were able to capture the spall behavior in the material (Figure 12); the location of the spall plane is compared in Table 7. As simulation models were not run for longer times, spall cracks did not develop completely. Location of the spall plane was measured from the back surface of the target plate to the start of spall crack plane.

Comparison of the free surface velocity profiles for the first $5 \mu$ s of both tests is presented in Figures 13 and 14. Free surface velocity profiles of the simulations and experiments were compared in terms of (a) elastic precursor wave and HEL, (b) plastic wave rise, (c) peak velocity, and (d) spall signatures, which were defined in Section 3. The values of these variables are listed in Table 8 . The results show that both LS-DYNA and CTH simulations captured the elastic precursor. However, both of these simulations showed lower HEL. Both LS-DYNA and CTH simulation showed sharper rise in the plastic wave. The slope of the simulation curves was steeper than that of the experimental velocity profile. Both LS-DYNA and CTH simulations were able to capture the pullback velocity signal after the second peak velocity, which determines spall strength of the material. However, the magnitude of the pullback velocity signal was significantly different from what was observed in the experiment, which may be due to the fact that the spall strength values used in both CTH and LS-DYNA simulations were based on
TABLE 7: Comparison of spall crack in simulations.

\begin{tabular}{lccc}
\hline $\begin{array}{l}\text { Impact } \\
\text { velocity } \\
(\mathrm{m} / \mathrm{s})\end{array}$ & Test ID & $\begin{array}{c}\text { Spall crack location } \\
\text { with } \\
\text { respect to free } \\
\text { surface }(\mathrm{mm})\end{array}$ & \% difference \\
\hline 5338 & $\begin{array}{c}\text { 1000-016 } \\
\text { LS-DYNA } \\
(10 \mu \mathrm{s})\end{array}$ & 2.3 & N/A \\
& CTH $(10 \mu \mathrm{s})$ & 2.6 & -19.6 \\
5063 & $1000-017$ & 2.4 & 13.0 \\
\hline \multirow{5}{*}{$\begin{array}{c}\text { LS-DYNA } \\
(10 \mu \mathrm{s})\end{array}$} & 2.3 & N/A \\
& $\mathrm{CTH}(10 \mu \mathrm{s})$ & 2.1 & -3.3 \\
\hline
\end{tabular}

the assumed similarity with the one-dimensional flier plate experiments. In both cases, CTH overestimated second peak in velocity profiles when compared to the corresponding LS-DYNA simulations. This difference can be explained by the fact that Eulerian-based hydrocode often had issues modeling broader set of physical behaviors and Lagrangian or coupled Eulerian-Lagrangian method was preferred in those cases [63], though both of these codes had their limitations comparing to the experimental velocity profiles.

\section{Conclusion}

Gas gun experiments were performed to measure the plastic deformation of A36 steel plates during hypervelocity impacts. The velocity of the back surface of plates was measured using a PDV system. Simulation models were developed in the LS-DYNA SPH solver and the CTH hydrocode. Both models used Johnson-Cook material model and the MieGrüneisen equation of state. A procedure for identifying the Hugoniot elastic limit and spall strength of A36 steel was presented. A study was conducted to determine SPH particle sensitivity, and CTH zone spacing studies were conducted to identify the best meshing strategy. The results showed that both simulation approaches were able to accurately match the physical measurements of impact cratering. Moreover, the simulations were able to predict the velocity profiles in the PDV experiments; however, some differences were observed. Additional experiments and fine-tuning of the simulation 
TABLE 8: Comparison of free surface velocities in simulations.

\begin{tabular}{|c|c|c|c|c|c|c|c|}
\hline $\begin{array}{l}\text { Impact } \\
\text { velocity } \\
(\mathrm{m} / \mathrm{s})\end{array}$ & Test ID & $\mathrm{HEL}(\mathrm{GPa})$ & $\%$ difference & $\begin{array}{c}\text { 1st peak } \\
\text { velocity }(\mathrm{m} / \mathrm{s})\end{array}$ & $\%$ difference & $\begin{array}{c}\text { 2nd peak } \\
\text { velocity }(\mathrm{m} / \mathrm{s})\end{array}$ & $\%$ difference \\
\hline \multirow{3}{*}{5338} & $1000-016$ & 1.22 & N/A & 243.0 & N/A & 195.0 & N/A \\
\hline & LS-DYNA $(5 \mu \mathrm{s})$ & 0.64 & -47.5 & 232.0 & -4.5 & 220.0 & 12.8 \\
\hline & $\mathrm{CTH}(5 \mu \mathrm{s})$ & 0.57 & -53.3 & 247.2 & 1.7 & 256.5 & 31.5 \\
\hline \multirow{3}{*}{5063} & $1000-017$ & 0.95 & N/A & 205.0 & N/A & 171.0 & N/A \\
\hline & LS-DYNA $(5 \mu \mathrm{s})$ & 0.64 & -32.6 & 228.9 & 11.7 & 195.1 & 14.1 \\
\hline & CTH $(5 \mu \mathrm{s})$ & 0.57 & -40.0 & 224.8 & 9.7 & 240.2 & 40.5 \\
\hline
\end{tabular}

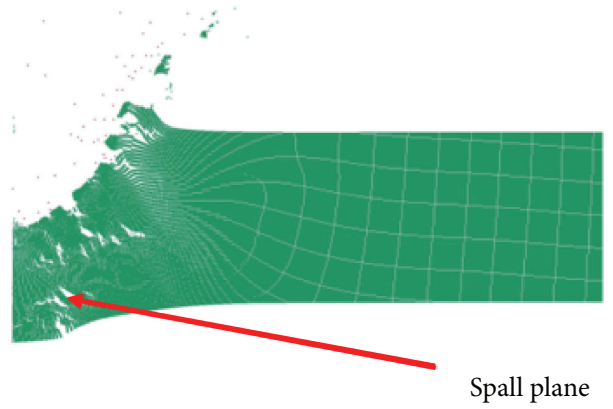

(a) LS-DYNA at $10 \mu \mathrm{s}$

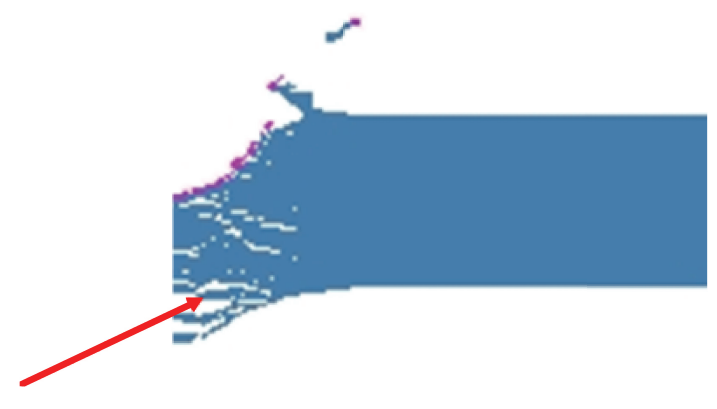

(b) $\mathrm{CTH}$ at $10 \mu \mathrm{s}$

FIGURE 12: Spall plane in Test 1000-017 simulations.

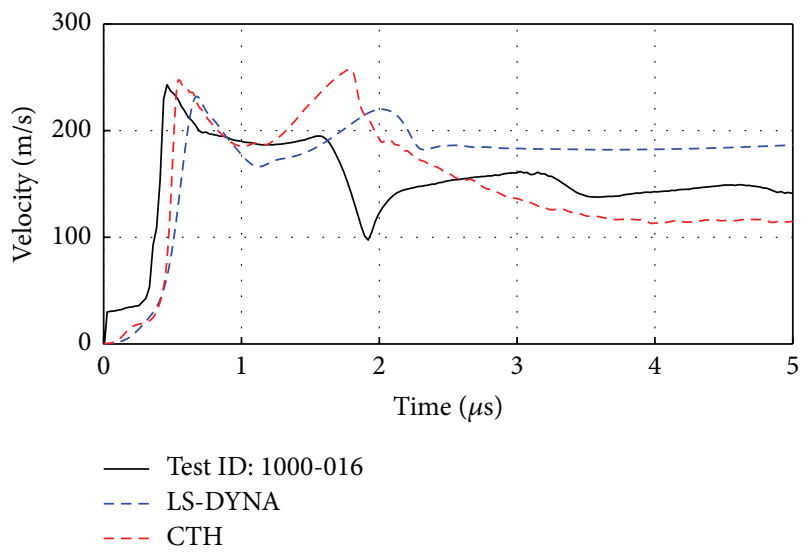

FIgURE 13: Free surface velocity comparison of Test 1000-016 (impact velocity: $5.338 \mathrm{~km} / \mathrm{s}$ ).

models were needed, including the use of more accurate material models and simulation parameters. Furthermore, studies were needed on the effect of the pressure induced $\alpha \leftrightarrow \varepsilon$ phase transition that is known to occur in pure iron.

\section{Conflict of Interests}

The authors declare that there is no conflict of interests regarding the publication of this paper.

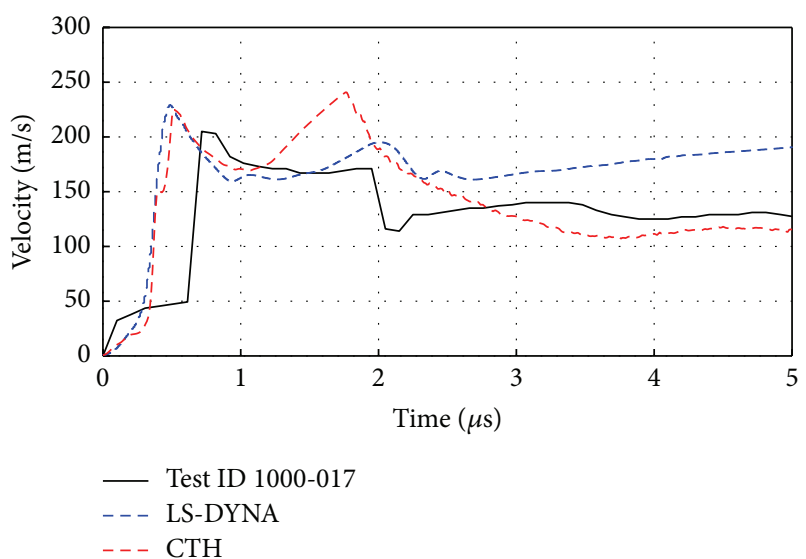

FIGURE 14: Free surface velocity comparison of Test 1000-017 (impact velocity: $5.063 \mathrm{~km} / \mathrm{s}$ ).

\section{Acknowledgments}

This study was conducted by National Security Technologies, LLC, under Contract no. DE-AC52-06NA25946 with the U.S. Department of Energy and supported by the Site-Directed Research and Development Program. The United States Government retains, and by accepting the article for publication, the publisher acknowledges that the United States Government retains, a nonexclusive, paid-up, irrevocable, worldwide license to publish or reproduce the published form of this work, or allow others to do so, for United States Government purposes (DOE/NV/25946-2392). 


\section{References}

[1] L. C. Chhabildas and M. D. Knudson, "Techniques to launch projectile plates to very high velocities," in High-Pressure Shock Compression of Solids VIII, L. C. Chhabildas, L. Davidson, and Y. Horie, Eds., High-Pressure Shock Compression of Condensed Matter, pp. 143-199, Springer, Berlin, Germany, 2005.

[2] C. Doolan, A Two-Stage Light Gas Gun for the Study of High Speed Impact in Propellants, Department of Defence, Salisbury, UK, 2001.

[3] N. Holmes, "Shocking," Gas-Gun Experiments STR:13-9, 2000.

[4] H. F. Swift, "Light-gas gun technology: a historical perspective," in High-Pressure Shock Compression of Solids VIII, L. C. Chhabildas, L. Davison, and Y. Horie, Eds., High-Pressure Shock Compression of Condensed Matter, pp. 1-35, Springer, Berlin, Germany, 2005.

[5] Z. Rosenberg and E. Dekel, Terminal Ballistics, Springer, 2012.

[6] J. H. Oscarson and K. F. Graff, Spall Fracture and Dynamic Response of Materials, Battelle Memorial Institute, Columbus, Ohio, USA, 1968.

[7] W. Goldsmith, T. W. Liu, and S. Chulay, "Plate impact and perforation by projectiles," Experimental Mechanics, vol. 5, no. 12, pp. 385-404, 1965.

[8] G. G. Corbett, S. R. Reid, and W. Johnson, "Impact loading of plates and shells by free-flying projectiles: a review," International Journal of Impact Engineering, vol. 18, no. 2, pp. 141-230, 1996.

[9] D. R. Christman and J. W. Gehrig, "Analysis of high-velocity projectile penetration mechanics," Journal of Applied Physics, vol. 37, article 1579, 1966.

[10] B. R. Sorensen, K. D. Kimsey, G. F. Silsby, D. R. Scheffler, T. M. Sherrick, and W. S. de Rosset, "High velocity penetration of steel targets," International Journal of Impact Engineering, vol. 11, no. 1, pp. 107-119, 1991.

[11] D. A. Shockey, D. R. Curran, and P. S. De Carli, "Damage in steel plates from hypervelocity impact. I. Physical changes and effects of projectile material," Journal of Applied Physics, vol. 46, no. 9, pp. 3766-3775, 1975.

[12] C. E. Anderson Jr., V. Hohler, J. D. Walker, and A. J. Stilp, "Time-resolved penetration of long rods into steel targets," International Journal of Impact Engineering, vol. 16, no. 1, pp. 118, 1995.

[13] J. W. Bond, Hypervelocity Impact Shock Induced Damage to Steel Armor, Defense Technical Information Center, Fort Belvoir, Va, USA, 1976.

[14] L. A. Merzhievskii and V. M. Titov, "Perforation of plates through high velogity impact," Journal of Applied Mechanics and Technical Physics, vol. 16, no. 5, pp. 757-764, 1975.

[15] T. Børvik, A. H. Clausen, O. S. Hopperstad, and M. Langseth, "Perforation of AA5083-H116 aluminium plates with conicalnose steel projectiles-experimental study," International Journal of Impact Engineering, vol. 30, no. 4, pp. 367-384, 2004.

[16] H. M. Wen and B. Lan, "Analytical models for the penetration of semi-infinite targets by rigid, deformable and erosive long rods," Acta Mechanica Sinica, vol. 26, no. 4, pp. 573-583, 2010.

[17] H. Wen, Y. He, and B. Lan, "Analytical model for cratering of semi-infinite metallic targets by long rod penetrators," Science China Technological Sciences, vol. 53, no. 12, pp. 3189-3196, 2010.

[18] Y. He and H. M. Wen, "A note on the penetration of semiinfinite metallic targets struck by long rods at high velocities," in Proceedings of the International Conference on Mechanical
Engineering and Material Science (MEMS '12), pp. 550-552, Atlantis Press, Shanghai, China, December 2012.

[19] L. M. Barker and R. E. Hollenbach, "Laser interferometer for measuring high velocities of any reflecting surface," Journal of Applied Physics, vol. 43, no. 11, pp. 4669-4675, 1972.

[20] L. M. Barker and R. E. Hollenbach, "Shock wave study of the $\alpha \rightleftarrows \varepsilon$ phase transition in iron," Journal of Applied Physics, vol. 45, article 4872, 1974.

[21] G. F. Kuscher, V. Hohler, and A. J. Stilp, "High-resolution velocity interferometer system for any reflector (VISAR) laser interferometer measurements of the rear side response of impact loaded steel plates," in Proceedings of the 15th International Congress on High Speed Photography and Photonics., vol. 0348 of Proceedings of SPIE, pp. 508-518, March 1983.

[22] J. L. Wise and L. C. Chhabildas, "Laser interferometer measurements of refractive index in shock-compressed materials," in Proceedings of the 4th American Physical Society Topical Conference on Shock Waves in Condensed Matter, Y. M. Gupta, Ed., pp. 441-454, Plenum Press, Spokane, Wash, USA, July 1986.

[23] M. J. Forrestal, L. M. Lee, and B. D. Jenrette, "Laboratoryscale penetration experiments into geological targets to impact velocities of $2.1 \mathrm{~km} / \mathrm{s}$," Journal of Applied Mechanics, vol. 53, no. 2, pp. 317-320, 1986.

[24] Z. Rosenberg and S. J. Bless, "Determination of dynamic yield strengths with embedded manganin gages in plate-impact and long-rod experiments," Experimental Mechanics, vol. 26, no. 3, pp. 279-282, 1986.

[25] A. K. Zurek, W. R. Thissell, J. N. Johnson, D. L. Tonks, and R. Hixson, "Micromechanics of spall and damage in tantalum," Journal of Materials Processing Technology, vol. 60, no. 1-4, pp. 261-267, 1996.

[26] M. D. Knudson, C. A. Hall, J. R. Asay, D. L. Hanson, J. E. Bailey, and W. W. Anderson, "Equation of state measurements in liquid deuterium to $70 \mathrm{GPa}$," Physical Review Letters, vol. 87, no. 22, Article ID 225501, 2001.

[27] T. J. Vogler and J. D. Clayton, "Heterogeneous deformation and spall of an extruded tungsten alloy: plate impact experiments and crystal plasticity modeling," Journal of the Mechanics and Physics of Solids, vol. 56, no. 2, pp. 297-335, 2008.

[28] D. Mukherjee, A. Rav, A. Sur, K. D. Joshi, and S. C. Gupta, "Shock induced spall fracture in polycrystalline copper," AIP Conference Proceedings, vol. 1591, pp. 608-610, 2014.

[29] O. T. Strand, D. R. Goosman, C. Martinez, T. L. Whitworth, and W. W. Kuhlow, "Compact system for high-speed velocimetry using heterodyne techniques," Review of Scientific Instruments, vol. 77, no. 8, Article ID 083108, 2006.

[30] B. Jilek, "History of velocimetry technology," in Proceedings of the 7th Annual Photonic Doppler Velocimetry Workshop (PDV '12), Sandia National Laboratory, Albuquerque, NM, USA, October 2012.

[31] R. Chau, J. Stölken, P. Asoka-Kumar, M. Kumar, and N. C. Holmes, "Shock hugoniot of single crystal copper," Journal of Applied Physics, vol. 107, no. 2, Article ID 023506, 2010.

[32] J. A. Zukas, High Velocity Impact Dynamics, vol. 1990, Wiley, 1990.

[33] G. R. Johnson and W. H. Cook, "A constitutive model and data for metals subjected to large strains, high strain rates and high temperatures," in Proceedings of the 7th International Symposium on Ballistics, pp. 541-547, The Hague, The Netherlands, 1983. 
[34] F. J. Zerilli and R. W. Armstrong, "Dislocation-mechanicsbased constitutive relations for material dynamics calculations," Journal of Applied Physics, vol. 61, no. 5, pp. 1816-1825, 1987.

[35] D. J. Steinberg and C. M. Lund, "A constitutive model for strain rates from $10^{-4}$ to $10^{6} \mathrm{~s}^{-1}$," Journal of Applied Physics, vol. 65, no. 4, pp. 1528-1533, 1989.

[36] B. Banerjee, "An evaluation of plastic flow stressmodels for the simulation of high-temperature and high-strain-rate deformation of metals," http://arxiv.org/abs/cond-mat/0512466.

[37] T. Børvik, O. S. Hopperstad, T. Berstad, and M. Langseth, "Numerical simulation of plugging failure in ballistic penetration," International Journal of Solids and Structures, vol. 38, no. 34-35, pp. 6241-6264, 2001.

[38] T. Børvik, M. Langseth, O. S. Hopperstad, and K. A. Malo, "Ballistic penetration of steel plates," International Journal of Impact Engineering, vol. 22, no. 9, pp. 855-886, 1999.

[39] T. Børvik, O. S. Hopperstad, T. Berstad, and M. Langseth, "A computational model of viscoplasticity and ductile damage for impact and penetration," European Journal of Mechanics, A/Solids, vol. 20, no. 5, pp. 685-712, 2001.

[40] X. W. Chen and Q. M. Li, "Perforation of a thick plate by rigid projectiles," International Journal of Impact Engineering, vol. 28, no. 7, pp. 743-759, 2003.

[41] X. W. Chen, Y. B. Yang, Z. H. Lu, and Y. Z. Chen, "Perforation of metallic plates struck by a blunt projectile with a soft nose," International Journal of Impact Engineering, vol. 35, no. 6, pp. 549-558, 2008.

[42] X. W. Chen, X. Q. Zhou, and X. L. Li, "On perforation of ductile metallic plates by blunt rigid projectile," European Journal of Mechanics-A/Solids, vol. 28, no. 2, pp. 273-283, 2009.

[43] J. Eftis and J. A. Nemes, "Modeling of impact-induced spall fracture and post spall behavior of a circular plate," International Journal of Fracture, vol. 53, no. 4, pp. 301-324, 1992.

[44] J. Zukas, Introduction to Hydrocodes, Elsevier, 2004.

[45] D. E. Grady and M. E. Kipp, "Experimental and computational simulation of the high velocity impact of copper spheres on steel plates," International Journal of Impact Engineering, vol. 15, no. 5, pp. 645-660, 1994.

[46] G. T. Camacho and M. Ortiz, "Adaptive lgrangian modelling of ballistic penetration of metallic targets," Computer Methods in Applied Mechanics and Engineering, vol. 142, no. 3-4, pp. 269301, 1997.

[47] D. J. Gee, "Plate perforation by eroding rod projectiles," International Journal of Impact Engineering, vol. 28, no. 4, pp. 377-390, 2003.

[48] R. A. Gingold and J. J. Monaghan, "Smoothed particle hydrodynamics: theory and application to non-spherical stars," Monthly Notices of the Royal Astronomical Society, vol. 181, no. 3, pp. 375389, 1977.

[49] J. L. Lacome, C. Espinosa, and C. Gallet, "Simulation of hypervelocity spacecrafts and orbital debris collisions using smoothed particle hydrodynamics in LS-DYNA," in Proceedings of the 5th Dynamics and Control of Systems and Structures in Space Conference, p. 9, Cambridge, UK, 2002.

[50] V. Mehra and S. Chaturvedi, "High velocity impact of metal sphere on thin metallic plates: a comparative smooth particle hydrodynamics study," Journal of Computational Physics, vol. 212, no. 1, pp. 318-337, 2006.

[51] F. Plassard, J. Mespoulet, and P. Hereil, "Hypervelocity impact of aluminium sphere against aluminium plate: experiment and LS-DYNA correlation," in Proceedings of the 8th European LSDYNA Conference, pp. 1-11, Strasbourg, Germany, May 2011.
[52] H. A. Kalameh, A. Karamali, C. Anitescu, and T. Rabczuk, "High velocity impact of metal sphere on thin metallic plate using smooth particle hydrodynamics (SPH) method," Frontiers of Structural and Civil Engineering, vol. 6, no. 2, pp. 101-110, 2012.

[53] K. Loft, M. C. Price, M. J. Cole, and M. J. Burchell, "Impacts into metals targets at velocities greater than $1 \mathrm{~km} \mathrm{~s}^{-1}$ : a new online resource for the hypervelocity impact community and an illustration of the geometric change of debris cloud impact patterns with impact velocity," International Journal of Impact Engineering, vol. 56, pp. 47-60, 2013.

[54] D. J. Littlewood, "Simulation of dynamic fracture using peridynamics, finite element modeling, and contact," in Proceedings of the ASME International Mechanical Engineering Congress and Exposition, pp. 1-9, Vancouver, Canada, November 2010.

[55] J. D. Seidt, A. Gilat, J. A. Klein, and J. R. Leach, "High strain rate, high temperature constitutive and failure models for EOD impact scenarios," in Proceedings of the SEM Annual Conference \& Exposition on Experimental and Applied Mechanics, p. 15, Society for Experimental Mechanics, Springfield, Mo, USA, June 2007.

[56] D. J. Steinberg, Equation of State and Strength Properties of Selected Materials, Lawrence Livermore National Laboratory, Livermore, Calif, USA, 1996.

[57] T. Elshenawy and Q. M. Li, "Influences of target strength and confinement on the penetration depth of an oil well perforator," International Journal of Impact Engineering, vol. 54, pp. 130-137, 2013.

[58] Livermore Software Technology Corporation (LSTC), LSDYNA Keyword User's Manual, vol. 1, Livermore Software Technology Corporation (LSTC), 971st edition, 2007.

[59] M. A. Zocher, P. J. Maudlin, S. R. Chen, and E. C. FlowerMaudlin, "An evaluation of several hardening models using taylor cylinder impact data," in Proceedings of the European Congress on Computational Methods in Applied Sciences and Engineering (ECCOMAS '00), vol. 53, pp. 1-20, Barcelona, Spain, September 2000.

[60] ASTM A36 Steel, Plate, March 2015, http://www.matweb.com/ search/datasheet.aspx? matguid $=\mathrm{afc} 003 \mathrm{f} 4 \mathrm{fb} 40465 \mathrm{fa} 3 \mathrm{df05129f0-}$ e88e6\&\&ckck=1\#x26; ckck=1.

[61] R. Panciroli, "Hydroelastic impacts of deformable wedges," in Dynamic Failure of Composite and Sandwich Structures, S. Abrate, B. Castanié, and Y. D. S. Rajapakse, Eds., vol. 192 of Solid Mechanics and Its Applications, pp. 1-45, Springer, Dordrecht, The Netherlands, 2013.

[62] M. Selhammar, "Modified artificial viscosity in smooth particle hydrodynamics," Astronomy and Astrophysics, vol. 325, no. 2, pp. 857-865, 1997.

[63] A. J. Ward, R. P. Nance, X. Xiao, A. D. Shirley, and J. R. Cogar, " $10+\mathrm{km} / \mathrm{sec}$ hypervelocity impact modeling with a lagrangian solver," in Proceedings of the IMPLAST Conference, Providence, RI, USA, October 2010. 


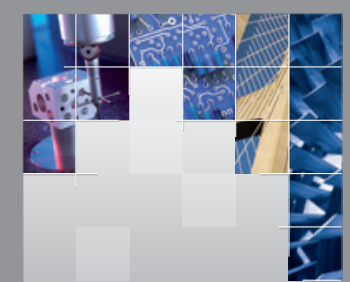

\section{Enfincering}
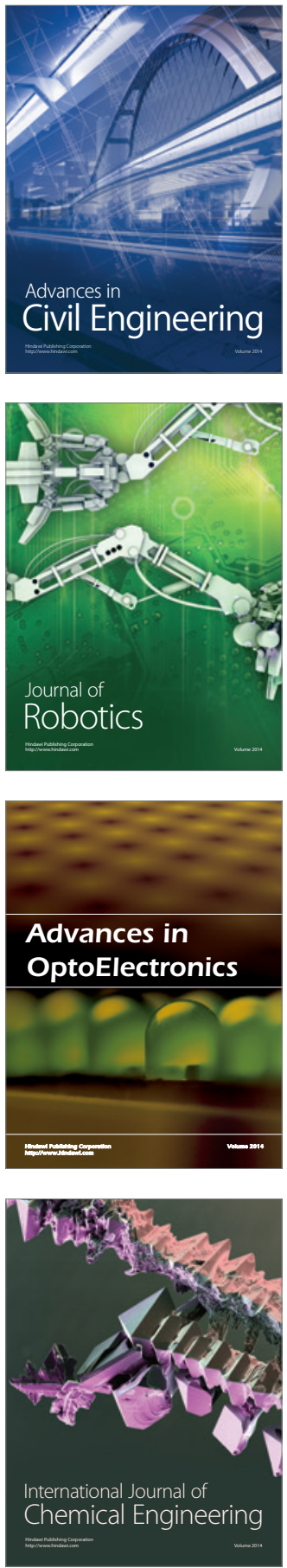

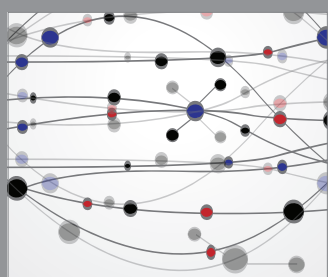

The Scientific World Journal

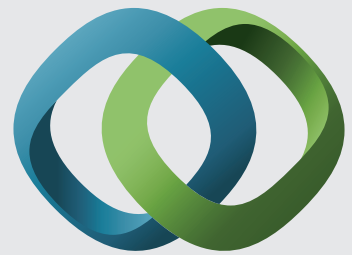

\section{Hindawi}

Submit your manuscripts at

http://www.hindawi.com
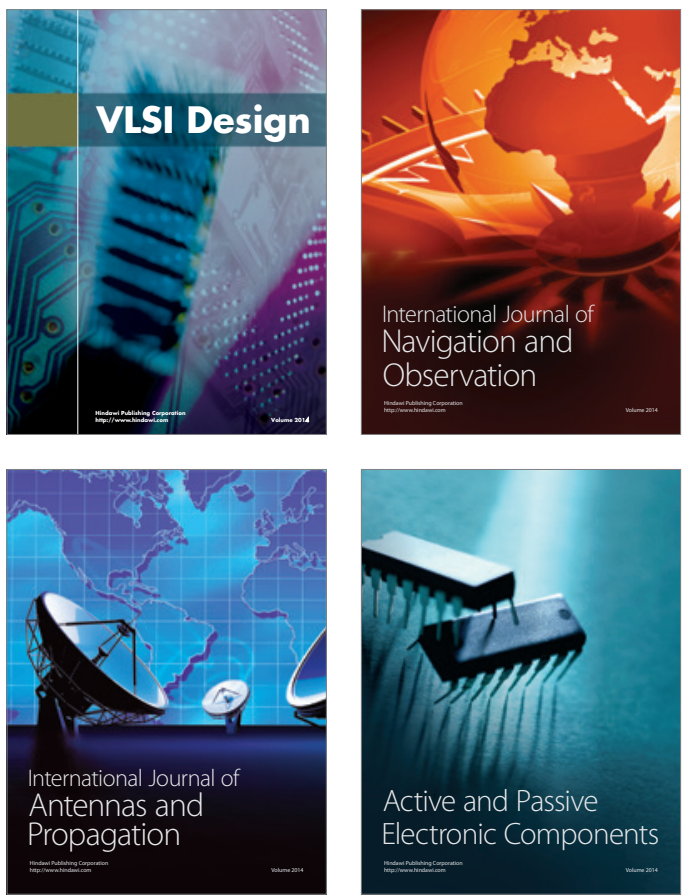
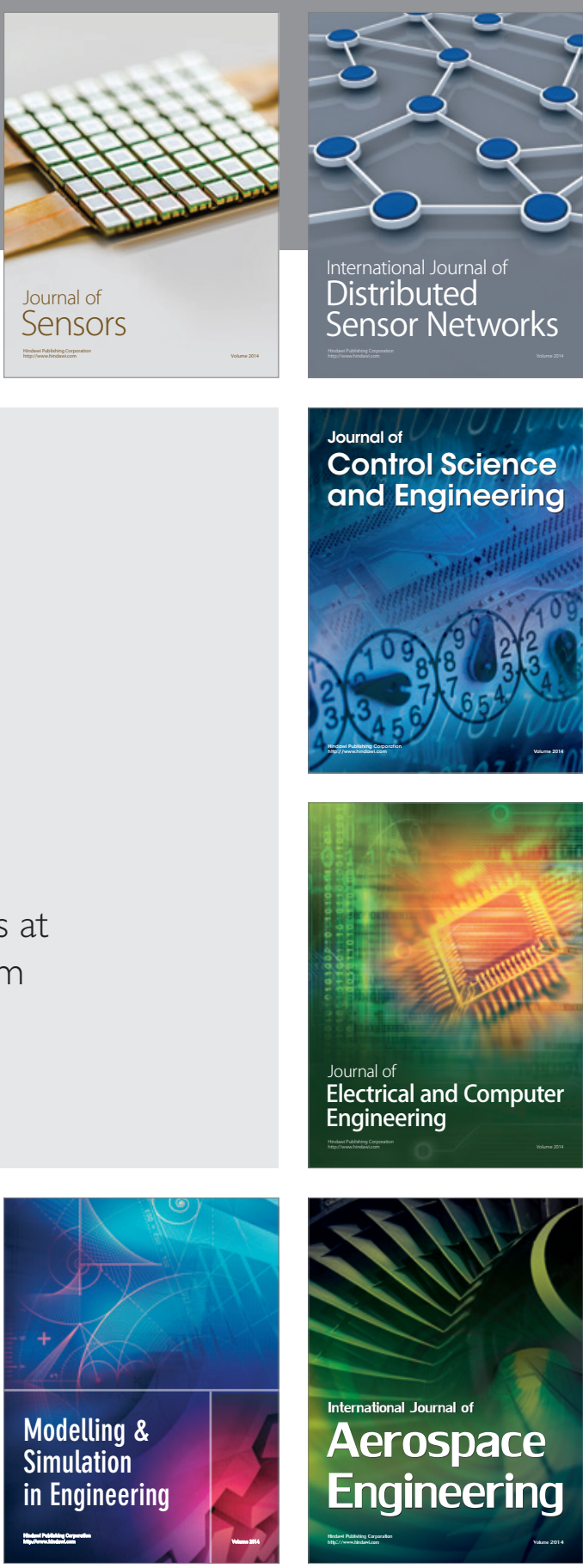

International Journal of

Distributed

Sensor Networks

Journal of

Control Science

and Engineering
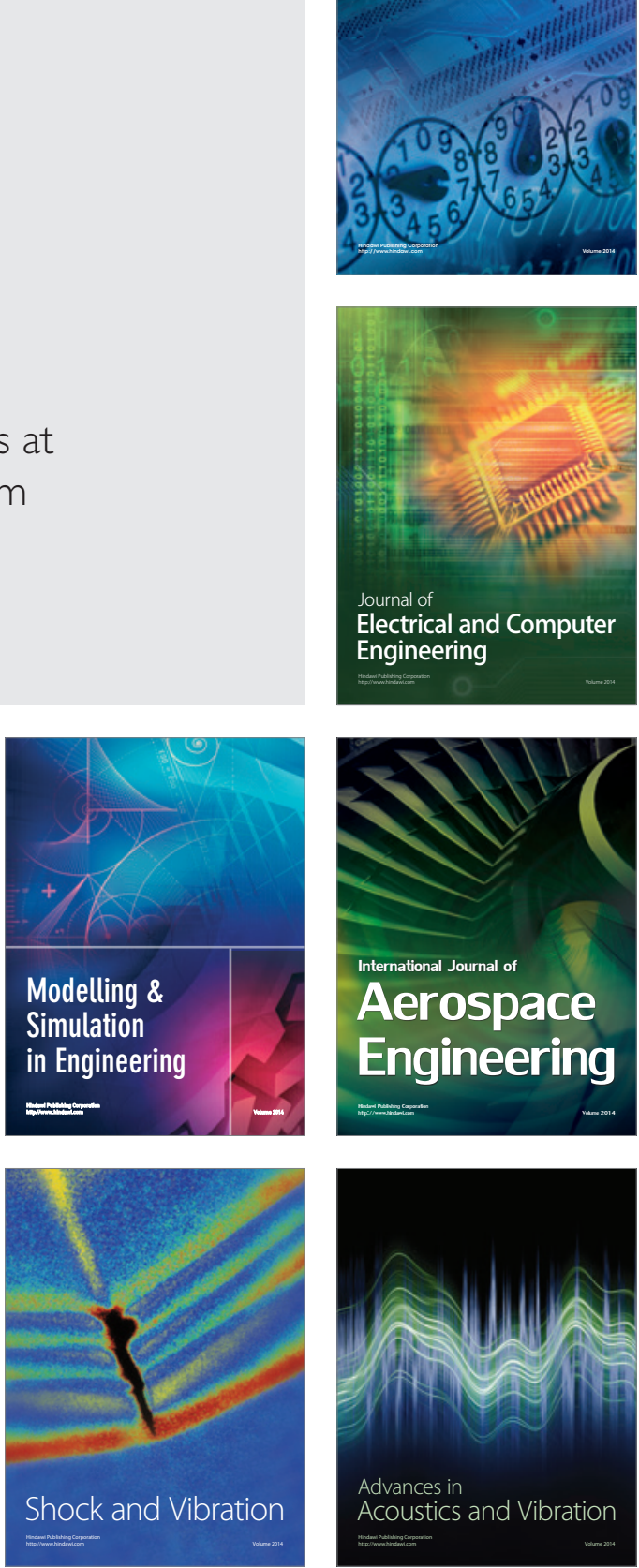